cứu trên một mẫu 508 trường hợp. Kết quả cho thấy $14 \%$ trường hợp đau bụng, $19 \%$ trường hợp có cảm giác khó tiêu, 15\% trường hợp buồn nồn, $9 \%$ trường hợp có biểu hiện tiêu chảy và $11 \%$ táo bón táo bón, $29 \%$ trường hợp bị đổ mồ hôi và $23 \%$ có biểu hiện nghiêm trọng là vấn đề khô miệng. Các tác dụng không mong muốn ảnh hưởng đến chất lượng cuộc sống và sinh hoạt hàng ngày của người bệnh bao gồm tăng cân, suy giảm chức năng tình dục và khó xuất tinh. ${ }^{8}$

\section{KẾT LUÂ̂N}

Trong nhóm nghiên cứu, Amitriptylin được sử dụng nhiều nhất với liều khởi đầu trung bình là $40,3 \pm 23,9 \mathrm{mg} / \mathrm{ngày}$ và liều cao nhất trung bình là $75,0 \pm 35,4 \mathrm{mg} /$ ngày. Tiếp theo là Remeron với liều khởi đầu trung bình là $30,0 \pm 13,6$ $\mathrm{mg} / \mathrm{ngày}$ và liều cao nhất là $47,6 \pm 14,8$. Tác dụng không mong muốn thường gặp nhất của nhóm thuốc chống trầm cảm là khô miệng $(62,1 \%)$.

Lời cảm ơn. Tôi xin chân thành cám ơn 66 người bệnh rối loạn sự thích ứng với phản ứng trầm cảm ngắn, Viện Sức khỏe Tâm thần Quốc Gia, Bệnh viện Bạch Mai đã tạo điều kiện cho việc thực hiện nghiên cứu.

TÀI LIỆU THAM KHẢO
1. Association AP. Diagnostic and Statistical Manual of Mental Disorders, 5th Edition: DSM5. 5th edition. American Psychiatric Publishing; 2013.

2. Presicci A, Lecce $P$, Ventura $P$, Margari $F$, Tafuri S, Margari L. Depressive and adjustment disorders - some questions about the differential diagnosis: case studies. Neuropsychiatr Dis Treat. 2010;6:473-481.

3. Jones $R$, Yates WR, Williams $S$, Zhou $M$, Hardman L. Outcome for adjustment disorder with depressed mood: comparison with other mood disorders. J Affect Disord. 1999;55(1):55-61. doi:10.1016/s0165-0327(98)00202-x

4. Strain JJ, Diefenbacher A. The adjustment disorders: the conundrums of the diagnoses. Compr Psychiatry. 2008;49(2):121-130. doi:10.1016/j.comppsych.2007.10.002

5. Nguyễn Hoàng Yến. Nghiên cứu đặc điểm lâm sàng rối loạn sự thích ứng ở bệnh nhân điều trị nội trú tai Viên Sức khỏe Tâm thần. Published online 2015.

6. Zelviene $\mathbf{P}$, Kazlauskas E. Adjustment disorder: current perspectives. Neuropsychiatr Dis Treat. 2018;14:375-381. doi:10.2147/NDT.S121072

7. Hameed U, Schwartz TL, Malhotra K, West RL, Bertone F. Antidepressant treatment in the primary care office: outcomes for adjustment disorder versus major depression. Ann Clin Psychiatry Off J Am Acad Clin Psychiatr. 2005;17(2):77-81. doi:10.1080/10401230590932344

8. Ramic E, Prasko S, Gavran L, Spahic E. Assessment of the Antidepressant Side Effects Occurrence in Patients Treated in Primary Care. Mater Socio-Medica. 2020;32(2):131-134. doi:10.5455/msm.2020.32.131-134

\title{
SO SÁNH KẾT QUẢ ĐIỀU TRI DỰ PHÒNG HUYẾT KHỐI SAU PHẪU THUÂTT BẰNG HEPARIN TRỌNG LƯỢNG PHÂN TỬ THẤP VÀ RIVAROXABAN
}

\section{TÓM TẮT}

Mục tiêu: So sánh kết quả điều tri dư phòng huyết khối tĩnh mạch sau phâuu thuật bắng heparin trọng lượng phân tử thấp (LMWH) và rivaroxaban. Đối tướng và phương pháp nghiên cứu: Hồi cứu $30.010 \mathrm{NB}$ phẫu thuật >18 tuổi từ $1 / 1 / 2017$ đến 31/9/2018 được điều tri chống đông bằng LMWH hoăc rivaroxaban. Trong đó 25479 NB dự phòng bằng LMWH và 4531 NB dự phòng bằng rivaroxaban. Kêt quả nghiên cứu: Nhóm NB bị HKTM sau phẫu thuật của nhóm LMWH 0,6\% (146/25479) cao hơn nhóm

${ }^{1}$ Trường Đại học Y Hà Nội

${ }^{2}$ Bênh viên Đai họ Y Hà Nôi

Chiu trách nhiệm chính: Bùi Mỹ Hạnh

Email: buimyhanh@hmu.edu.vn

Ngày nhận bài: 10.9.2021

Ngày phản biên khoa họ: 15.11.2021

Ngày duyệt bài: 24.11.2021
Bùi Mỹ Hạnh ${ }^{1,2}$, Nguyễn Thị Minh Lý ${ }^{1,2}$ rivaroxaban $0,3 \%(15 / 4531)$ và tỉ lệ NB mắc HKTM trong 90 ngày sau ra viện của nhóm LMWH $0,5 \%$ $(138 / 25479)$ cao hơn nhóm rivaroxaban 0,3\% (14/4531). Có $6,2 \%$ (1585/25479) NB dự phòng LMWH có xuất hiện biến chứng xuất huyết nhiều hơn nhóm rivaroxaban có $4,5 \%(206 / 4531)$. Sự khác biệt có ý nghĩa thống kê với $\mathrm{p}<0,05$. Kết luận: Rivaroxaban làm giảm tỷ lê tái phát HKTM và khổng làm tăng nguy cơ xuất huyết ở $\mathrm{BN}$ sau phẫu thuật so với LMWH, sự khác biệt có ý nghĩa thống kê.

Tì̛ khóa: rivaroxaban, LMWH, Heparin trọng lượng phân tử thấp, surgery

\section{SUMMARY \\ LOW MOLECULAR WEIGHT HEPARIN COMPARED TO ANTICOAGULANT \\ RIVAROXABAN FOR THE PREVENTION OF VENOUS THROMBOEMBOLISM IN POSTOPERATIVE PATIENT}

Objectives: To compare the results of 
postoperative venous thromboembolism prophylaxis with low molecular weight heparin (LMWH) and rivaroxaban. Subjects and methods: The study was design retrospectively, 30,010 surgical patients with $>18$ years of age were recruited from January 1, 2017 to September 31, 2018 to received anticoagulation with LMWH or rivaroxaban. Of these, 25.479 patients were prevented by LMWH and 4.531 patients were prevented by rivaroxaban. Result: The number of postoperative VTE patient accounting for $0,6 \%$ in LMWH group (146/25479), which was higher than the figure of rivaroxaban group of $0,3 \%(15 / 4531)$ and the proportion of patients developing VTE in 90 days after hospital discharge of the LMWH group was 0,5\% $(138 / 25479)$, compared to rivaroxaban group with percentage of $0,3 \%$ (14/4531).The rate of developing bleeding complications were higher in LMWH prophylactic group with $6,2 \%(1585 / 25479)$ in comparison with rivaroxaban group with $4,5 \%$ (206/4531). The difference was statistically significant with $p<0.05$. Conclusion: Rivaroxaban reduced the rate of VTE recurrence and did not increase the risk of bleeding complication in postoperative patients compared with LMWH, the difference was statistically significant.

Keyword: Rivaroxaban, Low molecular weight heparin, surgery

\section{I. ĐẶT VẤN ĐỀ}

Huyết khối tĩnh mạch hiện là mối đe dọa cho các người bệnh phẫu thuật và là gánh nặng cho các hệ thống chăm sóc y tế trên thế giới [1]. Biến chứng này hiếm gặp, và hoàn toàn có thể dự phòng cũng như tránh được gánh năng chi phí, tỷ lệ nhập viện lại và thời gian nằm viện. Tại Việt Nam, tî lệ mắc HKTM trong và sau phẫu thuật theo tác giả Bùi Mỹ Hạnh năm 2019 là $0,1 \%$ [2] với chi phí gia tăng có thể lên tới hàng triệu USD [3]. Chính vì vậy, dự phòng huyết khối tĩnh mạch ở người bệnh phẫu thuật là hết sức cần thiết. Cùng với các biện pháp cớ học, một số thuốc kháng đông có thể được dùng để phòng ngừa huyết khối tĩnh mạch với thời gian dự phòng có thể kéo dài tới 35 ngày sau phẩu thuật [4]. Ơ Việt Nam, Hội tim mạch quốc gia năm 2016 đã đưa ra khuyến cáo hướng dẫn điều trị dự phòng HKTM nhưng chưa có nghiên cứu nào quy mô lớn so sánh về hiệu quả của rivaroxaban và LMWH ở người bệnh sau phẫu thuật. Để không ngừng nâng cao chất lượng và kết quả điều trị chúng tôi thực hiện nghiên cứu này với mục tiêu "So sánh kết quả điều trị dự phòng huyết khối sau phẫu thuật băng thuốc heparin trọng lượng phân tử thấp và rivaroxaban".

\section{II. ĐỐI TƯợNG VÀ PHƯƠNG PHÁP NGHIÊN CỨU \\ 1. Đối tượng nghiên cứu \\ Tiêu chuấn lựa chon. Người bệnh từ 18} tuổi trở lên từ $1 / 1 / 2017$ đến $31 / 9 / 2018$ được thực hiện phẫu thuật bao gồm: (1) Phẫu thuâtt thẩn kinh cột sống; (2) Phẫu thuật tim; (3) Phẫu thuật mạch; (4) Phẩu thuật tiết niệu; (5) Phẫu thuật tiểu hóa; (6) Phẫu thuật chấn thương chỉnh hình; (7) Phẩu thuật tạo hình. sau khi được chẩn đoán xác định HKTMS bằng siêu âm doppler tĩnh mạch hoặc chẩn đoán xác định TMP bằng chụp cắt lớp vi tính.

Người bệnh có dữ liệu trích xuất bệnh án theo yêu cầu định dạng chuyển đổi thống nhất lên cổng bảo hiểm từ $1 / 1 / 2017$ cho đến ngày 31/9/2018.

Người bệnh phẫu thuật được điều trị chống đông bằng LMWH hoặc rivaroxaban

Tiêu chuẩn loại trư. . Người bệnh đã trải qua phẫu thuật loại bỏ huyết khối, sử dụng lưới lọc tĩnh mạch chủ; hoặc nếu người bệnh có bất kỳ chống chỉ định nào liên quan đến sử dụng enoxaparin, hoặc thuốc kháng Vitamin K.

\section{Phương pháp}

a. Thiết kế nghiên cứu: Nghiên cứu hồi cứu

b. Cỡ mẫu và chọn mẫu. Áp dụng phương pháp chọn mẫu thuận tiện. Tất cả những người bệnh đạt tiêu chuẩn lựa chọn đều được đề xuất tham gia vào nghiên cứu.

Tổng cộng 30010 NB phẫu thuật 2 nhóm 25479 NB dự phòng bằng LMWH và 4531 NB dự phòng bằng rivaroxaban.

c. Tiêu chẩn chẩn đoán HKTM. HKTM trong lúc nằm viện đợt phẫu thuật và sau khi xuất viện bị tái nhập viện lại với chẩn đoán xác định mắc huyết khối tĩnh mạch trong thời gian nằm viện có mã bệnh ICD10 bao gồm huyết khối tắc mạch phổi (I26), bệnh viêm tĩnh mạch và tắc tĩnh mạch (I80), huyết khối tĩnh mạch cửa (I81), thuyên tắc và huyết khối tĩnh mạch khác (I82).

\section{d. Biến số}

- Tính hiệu quả: Tỉ lệ NB mắc HKTMS, TMP, HKTM sau điều trị bằng LMWH và riboxaban và sau ra viện đến 90 ngày.

- Tính an toàn: Tî lệ NB nhồi máu não sau điêu trị bằng LMWH và riboxaban

Tỉ lệ NB xuất huyết tiêu hóa sau điều trị bằng LMWH và riboxaban

Tỉ lệ NB bị xuất huyết khác sau điều trị bằng LMWH và riboxaban

Tî lệ $N B$ bị xuất huyết sau điều trị bằng LMWH và riboxaban

3. Xử lý số liệu: Dữ liệu được xử lý bằng phần mềm thống kề stata 16.0. Mố tả dưới dạng tần số tỷ lệ \%, sử dụng kiểm định Chi bình phương và Fisher test để đo lường sự khác biệt. Các kết quả có ý nghĩa thống kê khi $p<0,05$

4. Đạo đức nghiên cứu. Nghiên cứu được 
triển khai nhằm mục đích nâng cao chất lượng khám chữa bệnh. Thông tin người bệnh hoàn toàn được bí mật và tuân thủ các quy định thông tư 45/2017/TT-BYT. Được sự chấp thuân của Hôi đồng đạo đức trường Đại học Y Hà Nội. Số quyết định 67/HDDDDHYHN ngày 24 tháng 3 năm 2017.

\section{KẾT QUẢ NGHIÊN CỨU}

Bảng 3.13. Đặc điểm chung của 2 nhóm nghiên cứu

\begin{tabular}{|c|c|c|c|c|}
\hline \multicolumn{2}{|c|}{ Đắc điếm } & \multirow{2}{*}{$\begin{array}{c}\text { LMWH } \\
25479(100 \%)\end{array}$} & \multirow{2}{*}{$\begin{array}{c}\text { Rivaroxaban } \\
4531(100 \%)\end{array}$} & \multirow{2}{*}{ p-value } \\
\hline & $\mathbf{N}$ & & & \\
\hline \multirow{4}{*}{ Nhóm tuổi } & $18-40$ & $2664(10,5 \%)$ & $519(11,5 \%)$ & \multirow{4}{*}{$<0,001$} \\
\hline & $41-60$ & $7861(30,9 \%)$ & $1544(34,1 \%)$ & \\
\hline & $61-74$ & $7554(29,6 \%)$ & $1292(28,5 \%)$ & \\
\hline & $>74$ & $7400(29,0 \%)$ & $1176(26,0 \%)$ & \\
\hline \multirow{2}{*}{ Giới tính } & Nam & $13628(53,5 \%)$ & $2266(50,0 \%)$ & \multirow{2}{*}{$<0,001$} \\
\hline & Nữ & $11851(46,5 \%)$ & $2265(50,0 \%)$ & \\
\hline \multirow{7}{*}{ Loại phẫu thuật } & Thần kinh, cột sống & $913(3,6 \%)$ & $48(1,1 \%)$ & \multirow{7}{*}{$<0,001$} \\
\hline & Tim ngực & $3360(13,2 \%)$ & $19(0,4 \%)$ & \\
\hline & Mạch máu & $2774(10,9 \%)$ & $92(2,0 \%)$ & \\
\hline & Dạ dày, ruột & $5085(20,0 \%)$ & $98(2,2 \%)$ & \\
\hline & Thận tiết niệu & $966(3,8 \%)$ & $36(0,8 \%)$ & \\
\hline & Phấu thuật chỉnh hình & $12140(47,6 \%)$ & $4231(93,4 \%)$ & \\
\hline & Tạo hình & $241(0,9 \%)$ & $7(0,2 \%)$ & \\
\hline \multicolumn{2}{|c|}{ Nhập viện cấp cứu } & $6456(25,3 \%)$ & $1211(26,7 \%)$ & 0,048 \\
\hline \multirow{5}{*}{ Nhóm điểm caprini } & $0-<2$ & $158(0,6 \%)$ & $10(0,2 \%)$ & \multirow{5}{*}{$<0,001$} \\
\hline & $2-4$ & $9381(36,8 \%)$ & $635(14,0 \%)$ & \\
\hline & $5-6$ & $5327(20,9 \%)$ & $327(7,2 \%)$ & \\
\hline & $7-8$ & $3342(13,1 \%)$ & $1526(33,7 \%)$ & \\
\hline & $>8$ & $7271(28,5 \%)$ & $2033(44,9 \%)$ & \\
\hline \multirow{2}{*}{\multicolumn{2}{|c|}{$\begin{array}{c}\text { Suy tim } \\
\text { Mach máu nqoai vi }\end{array}$}} & $2848(11,2 \%)$ & $104(2,3 \%)$ & $<0,001$ \\
\hline & & $675(2,6 \%)$ & $19(0,4 \%)$ & $<0,001$ \\
\hline \multicolumn{2}{|c|}{ Liệt nửa người } & $109(0,4 \%)$ & $10(0,2 \%)$ & 0,041 \\
\hline \multicolumn{2}{|c|}{ Khớp } & $442(1,7 \%)$ & $132(2,9 \%)$ & $<0,001$ \\
\hline \multirow{2}{*}{\multicolumn{2}{|c|}{$\begin{array}{l}\text { Loét dạ dày } \\
\text { Tiếu đườna }\end{array}$}} & $3764(14,8 \%)$ & $499(11,0 \%)$ & $<0,001$ \\
\hline & & $2666(10,5 \%)$ & $379(8,4 \%)$ & $<0,001$ \\
\hline \multicolumn{2}{|c|}{ Biến chứng tiếu đường } & $62(0,2 \%)$ & $7(0,2 \%)$ & 0,25 \\
\hline \multicolumn{2}{|c|}{ Ung thư } & $2701(10,6 \%)$ & $151(3,3 \%)$ & $<0,001$ \\
\hline \multicolumn{2}{|c|}{ Ung thư di căn } & $127(0,5 \%)$ & $8(0,2 \%)$ & 0,003 \\
\hline \multicolumn{2}{|c|}{ Bệnh gan nhẹ } & $847(3,3 \%)$ & $134(3,0 \%)$ & 0,20 \\
\hline & Xơ gan & $64(0,3 \%)$ & $6(0,1 \%)$ & 0,13 \\
\hline \multicolumn{2}{|c|}{ Suy thân man } & $1182(4,6 \%)$ & $37(0,8 \%)$ & $<0,001$ \\
\hline \multicolumn{2}{|c|}{ Sa sút trí tuệ } & $31(0,1 \%)$ & $5(0,1 \%)$ & 0,84 \\
\hline Thiếu I & mao mach & $201(0,8 \%)$ & $32(0,7 \%)$ & 0,56 \\
\hline & cân & $439(1,7 \%)$ & $47(1,0 \%)$ & $<0,001$ \\
\hline RL nư & và điện giải & $171(0,7 \%)$ & $13(0,3 \%)$ & 0,002 \\
\hline & mpho & $60(0,2 \%)$ & $8(0,2 \%)$ & 0,44 \\
\hline & giáp & $47(0,2 \%)$ & $12(0,3 \%)$ & 0,26 \\
\hline & máu tủy & $339(1,3 \%)$ & $29(0,6 \%)$ & $<0,001$ \\
\hline & hịp tim & $1415(5,6 \%)$ & $111(2,4 \%)$ & $<0,001$ \\
\hline & a tim & $2089(8,2 \%)$ & $23(0,5 \%)$ & $<0,001$ \\
\hline Mạc & náu phối & $73(0,3 \%)$ & $7(0,2 \%)$ & 0,11 \\
\hline & uyết áp & $6744(26,5 \%)$ & $913(20,2 \%)$ & $<0,001$ \\
\hline Biến chứ & tăng huyết áp & $196(0,8 \%)$ & $19(0,4 \%)$ & 0,010 \\
\hline Bện & ông máu & $59(0,2 \%)$ & $9(0,2 \%)$ & 0,67 \\
\hline Bệnh & i mạn tính & $1061(4,2 \%)$ & $99(2,2 \%)$ & $<0,001$ \\
\hline & $\mathrm{h}$ thn & $1764(6,9 \%)$ & $221(4,9 \%)$ & $<0,001$ \\
\hline
\end{tabular}




\begin{tabular}{|c|c|c|c|}
\hline Tiền sư TMP & $9(<1 \%)$ & $0(0,0 \%)$ & 0,21 \\
\hline Tiền sứ HKTMS & $326(1,3 \%)$ & $15(0,3 \%)$ & $<0,001$ \\
\hline Tiền sứ HKTM & $343(1,3 \%)$ & $15(0,3 \%)$ & $<0,001$ \\
\hline
\end{tabular}

Nhận xét: Dự phòng huyết khối thuyên tắc tĩnh mạch tăng dần theo lứa tuổi. Những NB độ tuổi dưới 40 được dự phòng ít nhất, 10,5\% được dự phòng bằng LMWH và 11,5\% dự phòng rivaroxaban. Nam giới được dự phòng bằng LMWH nhiều hơn nữ $(53,5 \%$ và $46,5 \%)$ tuy nhiên tương đồng trong dự phòng bằng rivaroxaban. Phẫu thuật chỉnh hình là nhóm có số lượng dự phòng nhiều nhất bởi cả 2 thuốc LMWH và rivaroxaban $(47,6 \%$ với LMWH và $93,4 \%$ với rivaroxaban). Có khoảng $25 \%$ số người bệnh được dự phòng là những người bệnh cấp cứu. Điểm số Caprini ở người bệnh được dự phòng bằng LMWH là đa số ở mức 2-4 điểm nhưng đối với Rivaroxban các điểm chiếm tỷ lệ cao nhất là $>7$ điểm.

9 NB được điều trị dự phòng LMWH có tiền sử thuyên tắc tĩnh mạch phổi, $326(1,3 \%)$ có tiền sử huyết khối tĩnh mạch sâu và có 343 NB có tiền sử huyết khối trước đó. Chỉ có 15 NB trong nhóm dự phòng rivaroxaban có tiền sử huyêtt khối tĩnh mạch sâu và tiền sử huyết khối.

Bảng 3.14. Tính hiệu quả của LMWH và rivaroxaban ở NB phẫu thuật

\begin{tabular}{|c|c|c|c|}
\hline Tính hiệu quả & $\begin{array}{c}\text { LMWH } \\
(\mathbf{n = 2 5 4 7 9 )}\end{array}$ & $\begin{array}{c}\text { Rivaroxaban } \\
(\mathbf{n = 4 5 3 1 )}\end{array}$ & p-value \\
\hline TMP & $9(0,04 \%)$ & $3(0,07 \%)$ & 0,34 \\
\hline HKTMS & $132(0,5 \%)$ & $14(0,3 \%)$ & 0,062 \\
\hline HKTM (TMP+HKTMS) & $146(0,6 \%)$ & $15(0,3 \%)$ & 0,040 \\
\hline HKTM trong 30 ngày sau ra viện & $59(0,2 \%)$ & $5(0,1 \%)$ & 0,10 \\
\hline HKTM trong 60 ngày sau ra viền & $106(0,4 \%)$ & $11(0,2 \%)$ & 0,085 \\
\hline HKTM trong 90 ngày sau ra viện & $138(0,5 \%)$ & $14(0,3 \%)$ & 0,042 \\
\hline
\end{tabular}

Nhận xét: Tỉ lệ nhóm NB bị HKTM sau phẫu thuật của nhóm LMWH 0,6\% (146/25479) cao hơn nhóm rivaroxaban $0,3 \%(15 / 4531)$. Tỷ lệ nhóm NB bị HKTM trong 90 ngày sau ra viện của nhóm LMWH 0,5\% (138/25479) cao hơn nhóm rivaroxaban 0,3\% (14/4531).

Sự khác biệt có ý nghĩa thống kê với $p<0,05$.

Bảng 3.15. Tính an toàn của $L M W H$ và rivaroxaban ở NB phẫu thuật

\begin{tabular}{|c|c|c|c|}
\hline Tính an toàn & $\begin{array}{c}\text { LMWH } \\
(\mathbf{n = 2 5 4 7 9 )}\end{array}$ & $\begin{array}{c}\text { Rivaroxaban } \\
(\mathbf{n = 4 5 3 1 )}\end{array}$ & p-value \\
\hline Nhồi máu não & $1120(4,4 \%)$ & $183(4,0 \%)$ & $<0,001$ \\
\hline Xuất huyết tiêu hóa & $134(0,5 \%)$ & $9(0,2 \%)$ & $<0,001$ \\
\hline Xuất huyết khác & $278(1,1 \%)$ & $11(0,24 \%)$ & $<0,001$ \\
\hline Nhồi máu não+ xuất huyết tiêu hóa & $18(0,07 \%)$ & $2(0,04 \%)$ & $<0,001$ \\
\hline Nhồi máu não và xuất huyết khác & $32(0,1 \%)$ & $1(0,02 \%)$ & $<0,001$ \\
\hline Xuất huyết tiêu hóa + xuất huyết khác & $3(0,05 \%)$ & $0(0 \%)$ & $<0,001$ \\
\hline Biến chứng xuất huyết & $1585(6,2 \%)$ & $206(4,5 \%)$ & $<0,001$ \\
\hline
\end{tabular}

Nhân xét: 4,4\% (1120/25479) NB dự phòng bằng $\mathrm{LMWH}$ có biến chứng nhồi máu não cao hơn nhóm dự phòng bằng rivaroxaban $4 \%$ $(183 / 4531)$.

$0,5 \% 9134 / 25479)$ NB dự phòng bằng LMWH có biến chứng xuất huyết tiêuu hóa cao hơn nhóm dự phòng bằng rivaroxaban 0,2\% (9/4531).

$6,2 \%(1585 / 25479)$ NB dự phòng LMWH có xuất hiện biến chứng xuất huyết nhiều hơn nhóm NB dự phòng bằng rivaroxaban $4,5 \%$ (206/4531).

Sự khác biệt có ý nghĩa thống kê với p<0,05.

\section{BÀN LUÂ̂N}

Ngoài tính hiệu quả, môt thách thức luôn phải đối mặt là làm thế nào để sử dụng thuốc chống đông dự phòng HKTM hiệu quả mà không có nguy cơ gặp các biến chứng nặng khác như xuất huyết não, nhồi máu não (độ an toàn). Kết quả về tính hiệu quả và an toàn trong nghiên cứu như sau:

Tính hiêu quả. Kết quả của chúng tôi chỉ ra rằng tỉ lệ nhóm NB bị HKTM sau phẫu thuật của nhóm LMWH 0,6\% (146/25479) cao hơn nhóm rivaroxaban $0,3 \%(15 / 4531)$ và tỉ lệ $\mathrm{NB}$ mắc HKTM trong 90 ngày sau ra viện của nhóm LMWH $0,5 \% \quad(138 / 25479)$ cao hơn nhóm rivaroxaban 0,3\% (14/4531). Sự khác biệt có ý nghĩa thống kê với $p<0,05$. Rivaroxaban có tác dụng chống đông máu mạnh trong điêu trị dự phòng HKTM sau phẫu thuật với vai trò ức chế yếu tố Xa có tính chọn lọc cao, có thể ức chế 
cạnh tranh sự tự do và gắn kết của yếu tố Xa cũ̃ng như hoạt động của prothrombin [1]. Rivaroxaban được sử dụng bằng đường uống trực tiếp, đạt đỉnh 2 giờ sau khi uống với thời gian bán thải từ 4-6 giờ và được đặc trưng bởi thời gian điều trị rộng, sinh khả dụng cao, ổn định dược động học tốt và hiệu quả dự đoán được [5]. Kết quả nghiên cứu của chúng tôi phù hợp với nghiên cứu của Anhua Long và cộng sự năm 2014 trên NB phẫu thuật thay khớp gối khớp háng, tỷ lệ HKTM ở nhóm rivaroxaban thấp hơn đáng kể so với nhóm LMWH (4,9\% so với $8,6 \% ; p=0,008)$ và không có người bệnh nào trong nhóm rivaroxaban mắc biến chứng tắc mạch phổi, trong khi có $0,3 \%$ NB dùng LMWH mắc biến chứng tắc mạch phổi sau phẩu thuật; tuy nhiên, sự khác biệt giữa hai nhóm không có ý nghĩa thống kê $(p=0,192)$ [5]. Trong một nghiên cứu năm 2019 của chúng tôi về so sánh hiệu quả điều trị của rivaroxaban và nhóm điều trị chuẩn cho thấy HKTM tái phát xảy ra ở 3,6\% người bệnh trong nhóm rivaroxaban so với 4,8\% người điều trị chuẩn [4]. Một nghiên cứu của Hai-Feng Huang và cộng sự cho thấy rivaroxaban có thể làm giảm tỉ lề mắc HKTM so với enoxaparin sau phẫu thuật. Số lượng các trường hợp mắc TMP đã giảm $(p=0,0084)$ sau khi dùng rivaroxaban [6].

Tính an toàn. Biến chứng xuất huyết là những tác dụng không mong muốn được báo cáo phổ biến nhất trong các thử nghiệm lâm sàng về thuốc chống đông. Biến chứng chảy máu trong nghiên cứu của chúng tôi bao gồm chảy máu não, chảy máu sau phúc mạc và bất kỳ tình trạng chảy máu nào có thể dẫn tới tử vong, nhập viện, hoặc phải truyền máu. Một nghiên cứu tổng quan của Sean T năm 2012 đã chỉ ra rằng rivaroxaban có hiệu quả dự phòng HKTM cao hơn mà không làm tăng nguy cơ xuất huyết [7]. Kết quả của chúng tôi ra rằng NB dự phòng LMWH gây biến chứng xuất huyết sau phẫu thuật $(6,2 \%)$ cao hơn so với rivaroxaban (4,5\%).

Nghiên cứu của chúng tôi phù hợp với nghiên cứu của $M a$ G và cộng sự năm 2013 cho thây rivaroxaban - chất ức chể Xa trực tiếp có hiệu quả hơn trong việc ngăn ngừa HKTM so với LMWH sau phẩu thuật thay khớp gối khớp háng, mà không làm tăng nguy cơ xuất huyết lớn [6]. Gonez Outes và cộng sự cũng đưa ra kết luận tương tự sau khi thực hiện một đánh giá hệ thông và phân tích meta năm 2012, LMWH có nguy cơ chảy máu liên quan trên lâm sàng cao hơn với rivaroxaban [8]. Theo môt nghiên cứu của Uri Pollak năm 2019, LMWH không thích hợp cho những bệnh nhân có khuynh hướng chảy máu hoặc chảy máu tích cực vì nó làm tăng nguy cơ chảy máu và gây giảm tiểu cầu do heparin [1].

Điểm mạnh, điểm yếu. Đây là một nghiên cứu hồi cứu đầu tiên trên một quy mô lớn về so sánh hiệu quả và độ an toàn của rivaroxaban với LMWH ở người bệnh phẫu thuật tại Việt Nam với thời gian theo dõi sau ra viện tới 3 tháng. Nghiên cứu đã chỉ ra rivaroxaban có hiệu quả vượt trội so với LMWH trong việc ngăn ngừa huyết khối mà không làm tăng nguy cơ chảy máu. Tuy nhiên vẫn cần có các nghiên cứu tiến cứu, đa trung tâm, ngẫu nhiên có đối chứng trên quy mô lớn để cung cấp bằng chứng tin cậy hơn.

Ngoài ra, do hạn chế của thiết kế hồi cứu, nên đã không đánh giá sự tuân thủ thuốc của người bệnh tham gia nghiên cứu và không thể kiểm soát việc sử dụng các biện pháp dự phòng huyết khối cơ học sau khi xuất viện. Bền canh đó, nghiên cứu của chúng tôi mới chỉ phân tích thống kê cơ bản mà chưa có điều kiện ghép cặp những NB có đặc điểm tương đồng để chỉ ra rõ hiệu quả điêu trị của rivaroxaban và LMWH trên từng nhóm NB.

\section{KẾT LUÂ̂N}

Tỷ lệ dự phòng HKTM sau phẫu thuật của nhóm LMWH 0,6\% (146/25479) cao hơn nhóm rivaroxaban $0,3 \%(15 / 4531)$ và tỉ lệ mắc HKTM trong 90 ngày sau ra viện của nhóm LMWH $0,5 \%(138 / 25479)$ cao hơn nhóm rivaroxaban $0,3 \%$ (14/4531). 6,2\% (1585/25479) NB trong nhóm dự phòng LMWH có xuất hiện biến chứng xuất huyết nhiêu hơn nhóm rivaroxaban $4,5 \%$ (206/4531). Sự khác biệt có ý nghĩa thống kê với $\mathrm{p}<0,05$.

\section{TÀI LIÊU THAM KHẢO}

1. Uri Pollak (2019), "Heparin-induced thrombocytopenia complicating extracorporeal membrane oxygenation support: Review of the literature and alternative anticoagulants", J Thromb Haemost., 17(10), 1608-1622.

2. Bui My Hanh, Hung Duong Duc, Nguyen Hoang Hiep, Vinh Pham Quang et al. (2019), "Frequency and risk factor of lower-limb Deep Vein Thrombosis After major orthopedic surgery in Viet Nam patients", Open Access Macedonian Journal of Medical Sciences, 7(24), 125-129.

3. My Hanh Bui, Quang Cuong Le, Duc Hung Duong et al. (2020), "Economic burden of venous thromboembolism in surgical patients: $A$ propensity score analysis from the national claims database in Vietnam", Plos One, 15(4).

4. My Hanh Bui, Nguyen Truong Son, Pham Thanh Viet et al. (2019), "Oral Rivaroxaban Versus Standard Therapy in Acute Venous Thromboembolism Treatment for Vietnamese 
Patients", Open Access Maced J Med Sci, 7(24), 4255-4259.

5. Anhua Long, Lihai Zhang and Yingze Zhang (2014), "Efficacy and safety of rivaroxaban versus low-molecular-weight heparin therapy in patients with lower limb fractures", ] Thromb Thrombolysis, 38(3), 299-305.

6. Hai-Feng Huang, Shan-Shan Li and XianTeng Yang (2018), "Rivaroxaban versus enoxaparin for the prevention of venous thromboembolism after total knee arthroplasty",
Medicine, 97(48), 13465.

7. Sean T Duggan (2012), "Rivaroxaban: a review of its use for the prophylaxis of venous thromboembolism after total hip or knee replacement surgery", Am J Cardiovasc Drugs, 12(1), 57-72.

8. Gomez-Outes A, Terleira-Fernandez AI and Suarez-Gea ML (2012), "Dabigatran, rivaroxaban, or apixaban versus enoxaparin for thromboprophylaxis after total hip or knee replacement: systematic review, meta-analysis, and indirect treatment comparisons", BMJ, 344.

\section{NGHIÊN CỨU MộT Số YẾU TỐ LIÊN QUAN ĐẾN KIẾN THỨC VÀ THỰC HÀNH VỀ CHĂM SÓC SỨC KHỎE SINH SẢN CỦA PHỤ NỮ XÃ ĐẠI SƠN, HUYÊ̂N TỨ KỲ, TỈNH HẢI DƯƠNG}

\section{TÓM TẮT}

Mục tiêu: tìm hiểu một số yếu tố có liên quan đến kiến thức và thực hành về chăm sóc sức khỏe sinh sản (CSSKSS) của phụ nữ xã Đại Sơn, huyện Tứ Kỳ, tỉnh Hải Dương. Đối tượng và phương pháp: phỏng vấn 384 phụ nữ tuổi 15-49 tuổi trong giai đoạn sinh sản. Kết quả: có mối liên quan giữa hoc vấn với kiến thức CSSKSS (OR=1,79; $p=0,01)$, giứa nghề nghiệp với kiến thức CSSKSS $(\mathrm{OR}=3,16 ; \mathrm{p}=0,02)$; giữa kiến thức về SKSS và thực hành $(O R=3,6 ; p<0,01)$, giữa tiếp cân dich vu với thực hành CSSKSS $(\mathrm{OR}=3,16$; $<<$ $0,01)$; giữa tuối kết hôn với thực hành CSSKSS (OR= $2,02 ; p=0,02)$; giữa nghề nghiêp với thực hành CSSKSS (OR=3,7; $p=0,03)$; giữa tuổi với thực hành CSSKSS (OR $=1,9 ; p=0,03)$. Kết luân: Kiến thức về SKSS, nghề nghiệp (công chức, viên chức), tuổi (3039), khả năng tiểp cập dịch vụ có liên quan đến kiến thức và thức hành SKSS ở phu nữ tuổi 15-49.

Tư khóa: sức khỏe sinh sản, kiến thức, thực hành

\section{SUMMARY}

FACTORS RELATED TO KNOWLEDGE AND PRACTICE OF REPRODUCTIVE HEALTH CARE OF WOMEN IN DAI SON COMMUNE, TU KY DISTRICT, HAI DUONG PROVINCE

Objectives: to find out the factors related to the knowledge and practice of women reproductive health care (RHC) in Dai Son commune, Tu Ky district, Hai Duong province. Subjects and methods: interviewing 384 women in the reproductive period aged 15-49 years old. Results: there is a correlation between education and $\mathrm{RH}$ knowledge $(\mathrm{OR}=1.79$; $\mathrm{p}$

*Trung tâm y tế Huyện Tứ Kỳ, tỉnh Hải Dương

**Bệnh viện Trung ương Quân đội 108

Chiu trách nhiệm chính: Bùi Thu Huyền

Email: buihuyendanso@gmail.com

Ngày nhân bài: 13.9.2021

Ngày phản biên khoa họ: 12.11.2021

Ngày duyệt bài: 24.11.2021

\author{
Bùi Thị Huyền*, Đỗ Văn Chiến**
}

$=0.01$ ), between occupation and RH knowledge (OR $=1.79 ; \mathrm{p}=0.01$ ), between knowledge and practice $(\mathrm{OR}=3,6 ; \mathrm{p}<0,01)$, between the access to RHC service and practice of RHC $(\mathrm{OR}=3.16 ; \mathrm{p}<0.01)$; between age of marriage and the practice of $\mathrm{RH}(\mathrm{OR}=2.02 ; \mathrm{p}=$ $0.02)$; between occupation and practice of RHC (OR= $3.7 ; p=0.03)$; between age RHC practice $(\mathrm{OR}=1.9$; $p=0.03)$. Conclusion: Knowledge of reproductive health, occupation (civil servant, public official), age (30-39), ability to access service are related to knowledge and practice RHC.

Keywords: reproductive health, knowledge, practice

\section{I. ĐẶT VẤN ĐỀ}

"Sức khỏe sinh sản là sự thoải mái hoàn toàn về thể chất, tinh thần và xã hội, không chỉ đơn thuần là không có bệnh, tật hoặc tàn phế của hệ thống sinh sản." [4]. Phụ nữ là cốt Iõi của sự phát triển kinh tế và xã hội. Sức khỏe và cuộc sống của họ có ý nghĩa quan trọng đối với bản thân, gia đình và cộng đồng. Hơn nữa, sức khỏe và đời sống của phụ nữ là yếu tố cớ bản cho thế hệ tương lai, phụ nữ nắm giữ chức năng của sự sống là sinh đẻ và nuôi dạy con cái [5]. Chúng ta vẫn chưa chú ý đầy đủ để đảm bảo rằng họ có thể thực hiện những việc này một cách an toàn [3].

Nội dung về chăm sóc sức khỏe sinh sản khá phong phú, tuy nhiên trong khuôn khổ đề tài này, chúng tôi chỉ đi sâu vào nghiên cứu một số yếu tố liên quan đến kiến thức và thực hành về kế hoạch hoá gia đình và làm mẹ an toàn của phụ nữ xã Đại Sơn, huyện Tứ Kỳ, Hải Dương là vùng nông thôn thuộc tỉnh Hải Dương, vùng Đồng bằng sông Hồng với điều kiện kinh tế, xã hội đang trên đà phát triển song còn có những khó khăn, bất cập về công tác y tế, chăm sóc sức khỏe, công tác Dân số - kế hoạch hóa gia đình. Để tìm hiểu một số yếu tố liên quan, yếu tố 